\title{
ENSAYOS
}




\section{Hacia una gramatología hipertextual: teoría y tecnología de la Deconstrucción *}

Rocío Rueda Ortiz

\section{Resumen}

El presente artículo parte del supuesto de que las tecnologías del hipertexto transforman radicalmente tanto los sistemas de acceso y almacenamiento de información, las prácticas de lectura y escritura, como los modos y medios de interacción comunicativa; sin embargo, éstas tienen un déficit teórico que ha hecho que su masificación tenga versiones tergiversadas, incompletas y aún contradictorias de lo que esta tecnología realmente puede llegar a ser dentro de nuestra cultura. Por ello, es necesario intentar construir un fundamento teórico que permita orientar el sentido de dicha tecnología y al mismo tiempo incidir en los criterios de diseño e invención tecnológica. En la primera parte se describe la naturaleza tecnológica del hipertexto, sus potencialidades y algunas críticas sobre su uso en el campo educativo. En la segunda parte se realiza un ejercicio de transferencia conceptual desde la teoría de la Deconstrucción de Jacques Derrida, al campo de las nuevas tecnologías del hipertexto, entendidas como nueva escritura, como nuevo lenguaje de la cultura contemporánea. Finalmente se presentan unas breves implicaciones educativas.

\section{Palabras claves}

Hipertexto - cultura - comunicación - lectura - escritura

\section{Summary}

The present article starts with the assumption that hypertext technologies transform radically the access systems as well as the information storage; the reading and writing practices as well as the means and types of communicative interactions. However, these technologies have a theoretical deficit that have caused its massification to be misunderstood and incomplete to the point that they contradict what technology can really mean in our culture. In consequence, it is necessary to build a theoretical background to give sense of this technology and, at the same time, to impact technological design approaches. In the first part, the technological nature of hypertext, its potentialities and some critics about its educational use are described. In the second part, based on Jacques Derrida's deconstruction theory, so that they are understood as new writing, as new contemporary culture language. Finally, brief educational implications are presented.

\section{Key words}

Hypertext - culture - communication - reading - writing

\section{Presentación}

Como lo ha planteado Teófilo Neira (2000), las nuevas tecnologías se han instalado, se han desarrollado y crecido en el interior de ese potencial que ya tenía la escritura,

\footnotetext{
* Artículo recibido el 25 de abril de 2004 y arbitrado el 4 de mayo de 2004.

${ }^{1}$ Coordinadora del Programa de Posgrado de Comunicación-Educación de la Universidad Central. Doctora en el área de filosofía y teoría de la educación de la Universidad de las Islas Baleares, España. E-mail: rruedaortiz@yahoo.com
} 
destinado a fijar, recuperar, procesar y transmitir la información, pero diferenciándose cualitativamente de tecnologías anteriores. Esta es su primera y fundamental revolución. Constituyen un soporte nuevo, un medio de fijación totalmente distinto de los hasta ahora utilizados. Incorporan recursos que no habían sido diseñados, ni siquiera sospechados en épocas anteriores. "El lenguaje discurre por sus circuitos reflejándose en el parpadeo de las pantallas electrónicas, grabándose en procesadores diminutos, custodiándose en ordenadores cada vez más potentes y distribuyéndose mediante redes de alcance ilimitado. A los textos les están acompañando y les están sucediendo los hipertextos. Los hipertextos etimológicamente, son un "exceso" textual, un aumento y elevación del texto. Son los nuevos textos informáticos" (Neira, 2000: 4-5). Sin embargo, el hipertexto se nos presenta no sólo como una potenciación -o como la denominan algunos, reinvención- de las tecnologías de la escritura, sino que además modifica el orden de la narración, las formas y modalidades de las que puede revestirse, los elementos que lo acompañan y el tipo de discurso que se puede desarrollar, configurándose en escritura nueva.

\section{El hipertexto y la (re)invención de la escritura}

La hipertextualidad, digámoslo directamente, se refiere a la posibilidad de asociar y relacionar una parte de cualquier texto -sea escrito, visual, sonoro, gráfico- con cualquier otro texto almacenado de la misma manera. Activar un enlace de hipertexto normalmente significa hacer clic en una palabra subrayada (o palabra caliente, que también puede ser un icono o botón) que ordena al computador buscar una dirección escondida detrás del enlace, con texto asociado, sea en el mismo documento o en otra base de datos, o en otra web a la que se tiene acceso a través de la red. Cuando se implementa de forma completa, el hipertexto tiene la ventaja de que puede abarcar grandes -casi infinitosespacios de búsqueda.

Sin embargo, muchas de las personas que se encuentran por primera vez con la noción de hipertextualidad asumen que los enlaces son el factor más importante del hipertexto, sobre todo en comparación con el mundo de la tecnología impresa. Pero los enlaces no lo hacen todo, pues tal creencia nos haría caer fácilmente en una visión "enteractiva" de la hipertextualidad. No hay que olvidar que en la producción y en el uso de hipertextos es fundamental la cuestión de la retórica, de la organización no secuencial de la narrativa y la polifonía en la escritura.

Desde el punto de vista de George Landow (1997) la importancia fundamental del hipertexto en red para la realización de su potencial, sólo aparece cuando se le añade su último elemento clave: la capacidad por parte del lector de adicionar enlaces, comentarios o ambas cosas. "Vannevar Bush, Douglas Englebart, Ted Nelson, Andries Van Dam, coinciden en señalar que, en el hipertexto, las funciones del lector se funden con las de escritor y que la división entre ambos se va difuminando. La particular importancia de la textualidad en la red, se manifiesta cuando la tecnología convierte a los lectores en lectores-escritores o "lecautores" -wreader-, ya que cualquier contribución o cambio introducido por un lector pronto está al alcance de los demás lectores" (Landow, George, 1997: 32). Condición que para Landow hace que el hipertexto en la red tenga una característica democratizante dada esta nueva naturaleza tecnológica.

Tanto si se leen como dispositivos autónomos o como sistemas en red, los hipertextos pueden presentar dos estructuras fundamentalmente distintas: la primera depende básicamente de la del libro lineal (o libro electrónico aunque no sea una metáfora afortunada) y la segunda se corresponde con una organización dispersa en red y con centros múltiples, inherentes al enlazamiento electrónico. Si bien la mayoría de tramas 
hipertextuales existen como unidades relativamente separadas, en vez de ser nodos o regiones locales, dentro de un "docuverso" gigante, se pueden encontrar varios géneros como el didáctico, de consulta, constructivo, lúdico, literario, etc. Cada uno de ellos requiere de una estilística y proporciona al usuario una experiencia diferente; por ejemplo, mientras la utilización de obras de consulta como los diccionarios o las enciclopedias hipertextuales o multimedia implican sobre todo funciones de recuperación de información y provocan poca desorientación en el lector, ciertas formas de hipertextos convierten la exploración, el descubrimiento e incluso la desorientación en elementos cruciales en las relaciones con el usuario (especialmente aquí ubicamos los desarrollos de la denominada hiperficción) $)^{2}$.

Esta nueva naturaleza tecnológica disuelve la estabilidad fundamental que proporcionan las tecnologías impresas, por lo cual las "nuevas tecnologías" no deben considerarse simplemente como medios nuevos aplicados a obras inalteradas en su esencia (de ahí la impropiedad de la metáfora del libro electrónico). Desde nuestro punto de vista, intentar comprender cómo las obras cambian en el contexto de los distintos regímenes de la información implica, entre otras tareas, desenmarañar las relaciones entre las tecnologías de la información pasadas y presentes y los supuestos culturales, incluyendo nuestras nociones de literatura, de personalidad, teoría, poder y propiedad. También tendríamos que utilizar varios regímenes de información contra otros. Es decir, este nuevo entorno tecnológico subvierte los espacios convencionales de lectura, basados en un modelo de información individual, a favor de un modelo conectivista, sustituyendo el orden jerárquico de los libros por una red dinámica, colectiva y reconstruible.

Un segundo aspecto problemático se debe al hecho de que los lectores, que escogen su propio recorrido, leen todos textos distintos, y en algunos casos nunca leen la totalidad de texto disponible. Esto también replantea nuestra idea sobre el "dominio de un contenido". Es cierto que nunca se puede agotar o dominar completamente ningún texto impreso, pero al menos se puede afirmar haberlo leído todo o incluso haberlo leído las veces necesarias para lograr la credibilidad de conocerlo bien. Los grandes hipertextos, especialmente los que se encuentran en la red, ofrecen demasiadas "lexias" -o unidades completas de sentido- como para que se puedan leer en su totalidad. Se podría pensar entonces que la cantidad elimina la maestría y la autoridad, ya que sólo se puede obtener una muestra del texto, no dominarlo. En particular, el crítico tendrá que abandonar no sólo la idea de dominio, sino la de texto, y su objetividad en concreto. La voz de Barthes y Julia Kristeva nos resuenan aquí.

En efecto, vemos que muchas ideas postestructuralistas que en la cultura impresa resultan particularmente extrañas, pretenciosas o confusas ahora cobran sentido en el mundo del hipertexto, normalizándose incluso la mezcla y difusión de los géneros. Cuando Barthes, Gennete, Derrida y otros teóricos ponen en duda la frontera o barrera entre los textos teóricos y los literarios, sus afirmaciones entran aún en contravía para quienes consideran que sus teorias y afirmaciones roturan el saber tradicional; sin embargo, las observaciones de Barthes y de Foucault sobre la muerte del autor, las de Derrida sobre la textualidad, las de Kristeva sobre la intertextualidad, parecen ser connaturales al hipertexto ${ }^{3}$.

\footnotetext{
${ }^{2}$ Las novelas hipertextuales como Afternoon, de Michael Joyce y Victory Garden, de Stuart Moulthrop, difuminan todos los límites y se han convertido en paradigmáticas de este tipo de narración de hiperficción. Es posible acceder a éstas desde: www.eastgate/ubrown/literature/edu/html

${ }^{3}$ De hecho, podríamos sugerir algunas relaciones entre la naturaleza tecnológica de la hipertextualidad, su lenguaje y la "condición postmoderna". Características como la relacionabilidad y la multivocidad nos Digitalizado por RED ACADEMICA
} 
En el campo educativo y pedagógico, las investigaciones sobre el uso del hipertexto tienen resultados un tanto contradictorios. Por una parte, en su carácter más cognitivo, otorgan el mayor potencial del hipertexto en tanto sistema representacional de dominios de conocimiento a través de una red (conceptual o semántica) y de las posibles rutas de aprendizaje de los estudiantes. Se señalan entre otras fortalezas: a. El desarrollo del pensamiento asociativo, relacional, b. La integración significativa de viejos y nuevos conocimientos, c. El crecimiento de la autonomía en el aprendiz, d. La perspectiva multidimensional y polifónica, y e. El desarrollo de habilidades de búsqueda, acceso y almacenamiento eficiente de información. Estas potencialidades se han observado tanto en el uso de Internet con propósitos educativos, como en el uso de hipertextos didácticos para el aprendizaje de campos específicos de conocimiento ${ }^{4}$.

Los críticos y menos optimistas con los hipertextos cuestionan principalmente su poca incidencia en el desarrollo del pensamiento lógico, reflexivo y abstracto. Para estos, los jóvenes desarrollan una "hipermente" constantemente sometida a la superficialidad, a la velocidad, al estímulo visual y sonoro, disminuyendo, en general, el pensamiento crítico y las habilidades para comprender e interpretar datos. Se le señala negativamente su recurso a la emotividad, a la sensibilidad, más que a la razón y la sustitución del lenguaje conceptual por el lenguaje perceptivo, considerado más pobre no sólo por la disminución en el número de palabras, sino en cuanto a la riqueza de significados ${ }^{5}$. Entre estos polos se encuentra hoy el debate sobre el impacto del hipertexto en la cultura. Es visto como un nuevo ámbito de transformación cultural, a través de la polifonía de voces y la ruptura de las jerarquías de autor y lector y como propiciador de una cultura de mentes "superficiales", no comprometidas e irreflexivas.

Tales contradicciones creemos que se encuentran en gran medida ligadas a la metáfora teórica desde la cual se intenta comprender la hipertextualidad (tanto su conceptualización, como su diseño y producción tecnológica), esto es, desde la metáfora del libro, de la racionalidad y de la representación. Recordemos que el hipertexto emerge en contraposición a la escritura lineal y a su correlato, el pensamiento lógico. El hipertexto, al descentrar el texto y posibilitar "redes infinitas de lexias", está abriendo paso a una modalidad de pensamiento narrativo, cuya modalidad expresiva invita a explorar la imaginería, a revivir figuras retóricas para seducir, persuadir y captar los públicos. Más que un argumento lógico y verdadero, el hipertexto promueve relatos y narraciones; más que un gran libro sobre un campo de conocimiento, el hipertexto tiende puentes entre ciencia, tecnología, ficción y arte.

muestran, entre otros aspectos: 1. La conectividad histórica de la tecnología de la escritura; 2 . Los cambios en el desarrollo de competencias lecto-escritoras, en particular sobre las ideas de autor y de narratividad, en tanto esta adquiere un estatus válido como forma de conocimiento, y 3 . Las posibilidades de democratización y de libertad de opinión.

${ }^{4}$ Cf: Jonassen, David. "Hypertext Principles for Text and Courseware Design", en Educational Psychologist, 21 (4), 1993, pp 269-292.

Jonassen, David H., y Wang, Sherwood. "Acquiring structural knowledge from semantically structured hypertext”, en Journal of Computer-Based Instruction. Vol. 20, No. 1, 1993, pp. 1-8.

Rueda Ortiz, Rocío. Hipertexto: representación y aprendizaje. Bogotá: Tecné, Funorie, 1998.

${ }^{5}$ Campbell, Robert J. "HyperMinds for Hypertimes: the demise of rational, logical thought?", en Educational Techonology. Nueva Yersey, Vol. 38, No. 1, 1998, pp. 24-31.

Sartori, Giovanni. Homo Videns. La sociedad teledirigida. Madrid: Taurus, 1998. 
En consecuencia, nuestro punto de partida es que la hipertextualidad no es sólo un nuevo producto u objeto tecnológico, sino que es también un nuevo lenguaje que requiere pensarse desde teorías que rompan con los modelos que han acompañado a las tecnologías que lo precedieron y a sus correlatos de linealidad, centro, fijeza, univocidad y jerarquía. Y la teoría de la deconstrucción no sólo fisura tales modelos, sino que a la vez representa una caja de herramientas conceptual que nos permite dar un salto cualitativo en la comprensión que hasta ahora se ha tenido sobre el hipertexto en la cultura.

\section{2. (De)construyendo el hipertexto: Una gramatología hipertextual.}

Sin duda fue la lúcida exposición de George Landow en 1995, en su libro: El hipertexto: la convergencia entre la tecnología y la teoría crítica contemporánea, la que dejó señaladas las piedras de toque para lo que podría ser una fundamentación teórica del hipertexto, campo que venía siendo prácticamente exclusivo de los ingenieros o de la tecnología informática. Hoy, gracias a dicho trabajo, es posible encontrar vías de reflexión teórica interdisciplinar desde la filosofía, la teoría crítica literaria, la semiología y la pedagogía, entre otras. Landow abordó directamente algunos conceptos que podrían ser útiles para pensar la "naturaleza" del hipertexto, dándonos pistas sobre autores como Jacques Derrida, Roland Barthes y Julia Kristeva, entre otros. Pues bien, en nuestra búsqueda de tales fuentes teóricas encontramos que la teoría de la Deconstrucción es un marco conceptual pertinente a la hora de comprender el fenómeno de la hipertextualidad, entendida como escritura, como nuevo lenguaje ${ }^{6}$.

En breves palabras diríamos que la Deconstrucción señala la clausura de la metafísica en el pensamiento de occidente y representa una respuesta compleja a la variedad de movimientos teóricos y filosóficos del siglo $X X$, especialmente, de la fenomenonología husserliana, el estructuralismo de Saussure y el psicoanálisis de Freud y Lacan. Su tarea es la deconstrucción de la razón misma, pues para Derrida es necesario superar el logocentrismo que domina la cultura occidental $y$, en consecuencia, desnudar su fundamento. La deconstrucción interroga los presupuestos del pensar y de las instituciones; implica cuestionar el mito de la razón y su discurso y recuperar lo que se designa negativamente como la diferencia, la sinrazón, "lo otro", lo que no se deja someter a la identidad, o lo que Derrida ha denominado como la differánce ${ }^{7}$.

En el caso que nos ocupa, la deconstrucción señala en primer lugar la necesidad de inventar un concepto meta, una "archi-técnica" de las parejas naturaleza/técnica, cultura/técnica, humano/máquina que, en lugar de oponer los términos, supere la dualidad

\footnotetext{
${ }^{6}$ Dado el carácter de este artículo no desarrollaremos todas las herramientas conceptuales que hemos extraído de la teoría de la Deconstrucción y del lenguaje de Derrida, ni tampoco de su retraducción en lo que sería una post(e)pedagogía en la era de la cibercultura. En consecuencia, aquí sólo esbozamos algunas posibilidades interpretativas que dicha teoría nos aporta para comprender las tecnologías del hipertexto y evidenciar su potencial para la transformación cultural.

7 Como se sabe, la lógica de la metafísica tradicional funciona a partir de oposiciones fundamentales binarias: presencia-no presencia, ausencia-representación, cosa-imagen, dentro-fuera, contenidoexpresión, esencia-apariencia, inteligible-sensible, antes-después, originario-derivado, naturaleza-cultura, etc. Derrida niega tal juego de oposiciones. No existe lo perfecto y modélico. Hay que liberar al significante de la esclavitud que lo ata a un solo significado. El sentido carece de sentido. Los sentidos o significados son siempre cambiantes. El pensamiento de la "diferencia" surge por oposición al pensamiento de la "identidad". Genera, así, un pensamiento de la no presencia del ser y la verdad, y este planteamiento invitará a Derrida a considerar la tarea filosófica como un continuo proceso de desvelamiento de "suplementos" y a utilizar de buen grado el prefijo "archi" para designar el estatus de las nociones desconstruidas. Cf. Derrida, Jacques. De la gramatología. México: Siglo XXI, $4^{a}$ edición, 1986, $397 p$.
} 
jerarquizante en que se haya presa la técnica, pues ésta al oponerse a la naturaleza, a lo humano y a lo cultural ocupa el lugar del suplemento, mera extensión del hombre - de su fuerza-, y de la ciencia -como conocimiento aplicado-. En efecto, como saber secundario se lo ha reducido a los "objetivos" aparatos, utensilios y máquinas, desconociendo su imbricación con la cultura misma, con la cualidad del ser humano y, en consecuencia, negando que no es posible usar las técnicas sin "metamorfosearnos" con ellas y reinterpretarlas e inventarles nuevos usos.

De otro lado, Derrida critica las tesis logocéntricas que han solido presuponer una teoría tradicional del signo, basadas en sostener que éste unifica el carácter heterogéneo del significante y significado. En el origen no hay unidad, sino diferencia. El punto de partida está viciado por tal pretensión de verdad y de unidad. Por eso, el intento de Derrida nos es útil, pues apuesta por develar o, al menos neutralizar, el delirio de una razón omnipotente y omnisciente, que nos remite a un intento de abolir toda forma jerárquica, toda tiranía de una única voz. Tal presupuesto estructuralista está presente en las críticas que se le hacen al hipertexto por sus múltiples sentidos, o por su pluralidad "aberrante", como lo llaman algunos. Mas no es posible tal unidad de sentido en un texto, mucho menos en un hipertexto. No contamos con un sentido último y universal del lenguaje, sino con una multiplicidad inacabable de significados.

En este orden de ideas Derrida constata, en suma, que tanto palabras como conceptos participan en un complejo entramado histórico de diferencias, ausencias y presencias diferidas que, por otra parte, nunca han llegado a darse en estado puro. Este presupuesto estalla en la multiplicidad de contenidos de Internet. Enlaces que refieren una huella, una presencia a la que accedemos haciendo un clic, pero que al mismo tiempo se difiere, es una huella en la referencia a otros múltiples textos, a otros múltiples enlaces. La consecuencia más importante de ello es que la palabra plena ni ha existido ni existirá jamás, ni en el texto impreso, ni en el hipertexto. Por esta razón, señala Derrida, la paradoja de que la "escritura incluye el lenguaje", paradoja que se corporaliza en una ciencia de los signos, en la que sólo hay diferencias y huellas. Así, pues, el gram es el concepto más general en semiología, que deviene en gramatología. El gram, como unidad básica es equiparable a las lexias hipertextuales que rompen la continuidad, o la linealidad del discurso, y llevan necesariamente a una doble lectura: la del fragmento percibido en relación con su texto de origen y la del mismo fragmento incorporado a un nuevo conjunto, a una totalidad diferente.

Pues bien, este juego de referencias y esta fragmentación implican para Derrida que ningún elemento puede funcionar como signo sin referirse a otros elementos que no están presentes, y al mismo tiempo, todo elemento se constituye sobre la base de las trazas que sobre él han dejado los otros elementos de la cadena. La total y absoluta independencia semiótica de la escritura (los signos escritos existen y actúan con independencia de los agentes individuales o colectivos -autor/lector; emisor/receptor-), pero también de una intención significativa concreta. De ahí, que todo signo sea polisémico. Esta polisemia universal, dictada por la différance, es lo que Derrida denomina diseminación y se constituye en el tejido de trazas, de huellas, sobre cualquier significante, por lo cual nunca se puede conseguir una simple univocidad del significado. En efecto, puesto que la unidad de Derrida equivale al nexo, la gramatología es el arte y la ciencia de conectar y por lo tanto podemos decir que es el arte y la ciencia del hipertexto. No univocidad y polifonia de signos y medios, de lectores y escritores, es el escenario propio de la hipertextualidad, ahora comprendida bajo una teoría que supera la visión de la simple acumulación e interrelación de información en una gran máquina 
electrónica, por una perspectiva que replantea el centro mismo de cómo escribimos nuestra historia en la cultura.

Por supuesto una consecuencia de tal "inflación del signo" y de una Gramatología es la muerte del autor y el nacimiento del lector-autor. Para Derrida la escritura es legible reiterable- más allá de la muerte del destinatario. Está constituida, en su identidad de marca, por su iterabilidad, en la ausencia de autor o de todo sujeto empíricamente determinado. Esta expresión de iterabilidad signo y de ausencia del autor representa justamente el nacimiento de un nuevo lector-autor, que si bien ya se había propuesto antes en la semiología de Barthes, hoy adquiere un estatus más visible en la hipertextualidad. El sujeto se fragmenta, se multiplica, desaparece entre múltiples voces. Este es el (no)sujeto de Internet. El (no)sujeto de la tecnología del hipertexto.

De otro lado el concepto derridiano de intertextualidad, ese "todo que pone al texto en relación, manifiesta o secreta, con otros textos" ${ }^{8}$ hace que el discurso deje, pues, de considerarse en su singularidad para concebirse en su "trascendencia textual", de modo que un libro integra otro libro, y éste a otro, en una sucesión infinita. Vemos que la aproximación entre teoría literaria y desarrollo tecnológico es en este punto totalmente explícita: la hipertextualidad viene a objetivar la intertextualidad, de manera que esta idea va a ser el referente obligado en la literatura electrónica ${ }^{9}$. Como lo ha planteado Barthes, el texto es "descentralizado y sin cierre". Es decir, la metáfora del texto es también la de la red: si el texto (o hipertexto) se expande es bajo el efecto de una combinatoria, una sistemática. Por lo tanto, un texto, gracias a su capacidad de expansión en una pluralidad de significados que sobrepasa las coordenadas espacio-temporales, puede estar presente no en una, sino en varias obras. De ahí que el texto sea capaz de poner en conexión obras distintas, separadas por el espacio y por el tiempo, superando los límites de la propia historia.

¿Pero cómo se traduce esta intertextualidad en el hipertexto? Nuria Vouillamoz (2000:134), recuperando a Landow, nos lo describe audazmente: "además de la irrupción de elementos extra textuales, el hipertexto ofrece una renovación de las vías de acceso extra textuales, el hipertexto ofrece una renovación de las vías de acceso a la obra literaria al facilitar la plataforma técnica capaz de poner en práctica la vieja idea de intertextualidad: la lectura lineal queda sustituida por una navegación que permite establecer enlaces entre diferentes núcleos significativos -que pueden ser elementos textuales o elementos multimedia-". Esto también tiene una retraducción en las técnicas

\footnotetext{
${ }^{8}$ Genette, Gérard. Palimpsestos. La literatura en segundo grado. Madrid: Taurus, citado por Vouillamoz, Nuria. Literatura e Hipermedia. La irrupción de la literatura interactiva: precedentes y crítica. Barcelona: Paidós, 2000, pp. 84 y ss.

${ }^{9}$ Nuria Vouillamoz, en el libro de la nota 8, trae a este tema la alusión que muchas veces se hace desde el mundo de las comunicaciones al cuento de Borges la Biblioteca de Babel (1942), en el que Borges recrea la metáfora del universo como una gran Biblioteca: una biblioteca de diseño arquitectónico uniforme, sostenida sobre un número indefinido de galerías hexagonales invariables; una biblioteca eterna e infinita, capaz de albergar todos los libros, todas las posibles combinaciones de los veinticinco símbolos ortográficos. Vivir no es más que peregrinar: el hombre pasa su vida recorriendo la perfecta estructura de la Biblioteca en busca de un libro, quizás el "catálogo de los catálogos" que dé sentido a tan faraónica construcción. Emprende su peregrinación cambiando de un hexágono a otro, de un libro a otro, porque un libro conduce a otro libro, un libro enlaza con otro libro... y así hasta el infinito... Diríamos que es un proceso ilimitado en el que la intertextualidad queda transcendida para anticipar la hipertextualidad. Al respecto, Eco dice que Borges había superado la intertextualidad y había anticipado la era de la hipertextualidad, donde no sólo un libro habla sobre otro, sino donde además es posible acceder a un libro desde el interior de otro. Borges había perfilado con antelación el Word Wide Web, no tanto dibujando la forma de su biblioteca, sino prescribiendo en cada página la manera de navegar por ella.
} 
de lectura y escritura; es decir, tal intertextualidad implica la generación de estructuras discursivas de carácter multilineal en las que desaparecen las jerarquías dando pie a un texto, descentralizado. En este sentido, la posibilidad de acceder y navegar fácilmente de un nodo de información a otro supera las limitaciones de las publicaciones impresas y, a diferencia de un modelo secuencial de lectura, se propone un esquema modular que interrelaciona diferentes lexias. Esta ha sido una cualidad especialmente resaltada por Landow, pues para él la diferencia entre un texto impreso y un hipertexto es que, mientras aquél produce un esquema de lectura jerárquico y en cierto modo privilegia una única voz tiránica, el hipertexto rompe tal esquema indiferenciando los niveles y el estatus entre los textos principales y secundarios, lo cual produce una desmitificación del texto.

Ahora bien, Derrida pretende un estilo escritural picto-ideo-fonográfico (o, fonogramático, como lo ha denominado algunas veces) en el que integra tres niveles de comunicación: imágenes, juegos de lenguaje y discursos. Para sus detractores, es una subversión del lenguaje no funcional para las convenciones académicas. Sin embargo, nosotros encontramos que allí hay un fundamento muy interesante en términos de conocimiento productivo y entendimiento que debe ser explotado. Es decir, de lo que estamos hablando no es de un método de análisis o de criticismo -camino que han tomado muchos seguidores de Derrida-, sino, más bien, de una escritura para la invención, de una nueva retórica -y aún de creatividad- que sería la base para una nueva pedagogía asociada con una nueva escritura. La gramatología es un marco teórico dinámico pues, como Ulmer también ha indicado, incluye deconstrucción y escritura (entendida no sólo como una textualidad, sino como una práctica composicional/descomposicional), siendo una y otra operaciones complementarias: la gramatología, como extensión práctica de la deconstrucción y la deconstrucción como teoría.

En consecuencia, esta gramatología aplicada permite darle a la hipertextualidad un fundamento teórico que no sólo confía de nuevo en las imágenes (recordemos que el logos desconfía de ellas), sino que al integrar diferentes sistemas de signos, voz, imagen, texto, sonido, vídeo, animaciones, etc., establece una nueva condición de toda forma de lenguaje, liberado de cualquier privilegio del sentido y articulada a diferentes experiencias comunicativas. La hipertextualidad, desde una perspectiva gramatológica se convierte entonces en un producto (en proceso permanente) abierto e intertextual, dotado de un fuerte carácter suplemental de lenguajes. Los fragmentos o lexias, los enlaces o nexos, las tramas o trayectos de navegación y las redes se convierten en una forma de textualidad en la que la multiplicidad y la ambigüedad de los significados, se conservan despiertos como expresión de la inabarcable perplejidad, confusión y complejidad de la cultura contemporánea. Esta gramatología anuncia el nacimiento de una nueva escritura, de una escritura hipertextual que debería brindar no sólo al lenguaje y a sus áreas correlacionadas, sino, en general, a las ciencias humanas, una respuesta en relación con la era de las tecnologías de la información que estamos viviendo.

En síntesis, diremos que esta gramatología aplicada, o hipertextualidad, se sustentaría en una teoría cuya unidad es el gram (equiparable a la lexia de Barthes) y en el que cada elemento de lenguaje (texto, imagen, sonido, animación, etc.) funcionaría como suplemento. No hay centro ni privilegio de una única voz. La archiescritura, se traduce en una potencia de textualidad, siempre escindida, cuya práctica gramatológica hipertextual será la descomposición de lexias o unidades de sentido, y su (re)composición y multiplicación en axiles o ramas de redes de significados. Así mismo, esta gramatología transita hacia una modalidad de pensamiento narrativo, incluso de ficción, que trastroca las fronteras no sólo de espacio y tiempo, sino de campos de saber, discursos y públicos. 


\section{Una breve consideración educativa}

Un efecto directo de la deconstrucción derridiana es la puesta en evidencia de todo aquello que la cultura ha satanizado, olvidado, excluido, marginado y más aún, eliminado. Es decir, "lo otro" de la razón. Pues bien, en las tecnologías de la hipertextualidad al no operar centros, ni jerarquías, al no haber un discurso hegemónico -por lo menos fácilmente identificable- y al no tener restricciones de acceso y navegación (aunque ya se han iniciado acciones de restricción por edades, temáticas, prepagos, etc.) es un entorno no sólo de exploración identitaria para que quienes acceden a éste puedan "jugar" a "ser otros" -o a probar su ser otro-, sino que nos guste o no, lo aprobemos o no, es un ámbito en el que es posible que las minorías se expresen, aunque estas minorías sean skinheads hasta grupos indígenas latinoamericanos abogando por su supervivencia. Es decir, ese "otro" que el proyecto moderno excluyó por diferente (raro, extraño o inferior), la hipertextualidad se dispone a su visibilidad y narración. No hay una identidad última a la cual aspirar, o un modelo al cual imitar, ésta se dispersa en identidades minoritarias que ahora se escriben y (re)inscriben en el hipertexto.

En consecuencia, la cualidad heterofónica o de multiplicidad de voces y textos de la hipertextualidad requiere justamente de la diferencia; esto es, no hay una reducción a una sola identidad, sino que nos encontramos ante el despliegue de subjetividades, de diferencias, de minorías. Ahora bien, la apertura a esos "otros" de la razón, a esas múltiples identidades, es la condición propia de la subjetividad virtual, de la subjetividad que se despliega en el territorio hipertextual. Hay sobretodo simulaciones, exploraciones del yo que buscan un reconocimiento individual o colectivo, en minoría o en los márgenes. Es por ello que para Landow, por ejemplo, la hipertextualidad es un entorno comunicativo en el que se puede ejercer una nueva politeia, donde se puede aspirar a una cultura mucho más democrática y democratizante. Derrida considera que es urgente una perspectiva político-económico-científico-tecnológica sobre las tecnologías de la información. Para nosotros, sin duda, el hipertexto no puede ser considerado solamente como un dispositivo tecnológico, tiene implicaciones políticas, culturales, sociales y educativas que nos obligan a tener una visión compleja de su inserción en la cultura.

En este sentido vemos que ligada a la hipertextualidad está la necesidad de formación de pensamiento crítico, pues la diferencia, el reconocimiento del "otro", favorece la construcción de criterios para actuar con el entorno. ¿De qué vale una educación donde todos somos iguales bajo el supuesto de la negación de los "otros diferentes"? El otro, el excluido, el eliminado porque no se adapta a los moldes de la razón, de la Ley, al que la educación se ha tapado los ojos por su "a-normalidad", hoy adquiere una presencia, virtual, "diferida" y cuya "huella", o "fantasma", en palabras de Derrida, es susceptible de ser escrita, de ser (de)construida y re-escrita, y reinscripta en la cultura. La búsqueda de identidad y de homogeneidad no tiene cabida en los ambientes hipertextuales, no es posible hallar una presencia última a la cual orientar dicha acción; por el contrario, una acción educativa hipertextual actúa señalando la diferencia, las oposiciones de conceptos, su inversión y su posible desplazamiento. Así, por ejemplo, la lógica que relaciona lo humano con lo técnico, la ciencia con la tecnología, la naturaleza con la tecnología o la tecnología con la cultura es más bien un enjambre de paradojas que requieren ser desconstruidas desde la escuela (desmontadas, desnaturalizadas, analizadas, invertidas, neutralizadas), de tal manera que podamos asumir una actitud crítica e inventiva ante éstas. En definitiva, una potencialidad educativa que tienen las tecnologías de la hipertextualidad en la red es la posibilidad de deconstruir textos a través de su oposición, confrontación, desmontaje y traducción a otras lenguas, lenguajes y contextos de producción de sentido, haciendo entonces visibles esos "otros" de la historia, 
de la ciencia, de la vida cotidiana, del arte, en fin, de la cultura, que han estado ocultados u olvidados. Como se ve, se trata de una pedagogía que actúa en los márgenes, en la deconstrucción y la (re)construcción de sujetos y saberes.

\section{Referencias bibliográficas}

Barthes, Roland. Elementos de semiología. Madrid: Alberto Corazón, 1971.

Derrida, Jacques. Cómo no hablar y otros textos. Barcelona: Proyecto A, 1997, p. 159. . De la gramatología. México: Siglo XXI, 4ª edición, 1986, p. 397.

Espectros de Marx. El estado de la deuda, el trabajo del duelo y la nueva internacional. Madrid: Trotta, 1998.

. Mal de archivo. Una impresión freudiana. Madrid: Trotta, 1997.

Landow, George P. Hipertexto. La convergencia entre la teoría crítica contemporánea y la tecnología. Barcelona: Paidós, 1995.

. Teoría del hipertexto. Barcelona: Paidós, 1997.

Lévy, Pierre. ¿Qué es lo virtual?. Barcelona: Paidós, 1999.

. "Sobre la cibercultura", en Revista de Occidente. No. 206, 1998, pp.13 y ss.

Rodríguez Neira, Teófilo. "Textos e hipertextos”, en Aula Abierta, No. 75, junio 2000, pp. 3-26.

Vouillamoz, Nuria. Literatura e Hipermedia. La irrupción de la literatura interactiva: precedentes y crítica. Barcelona, Paidós, 2000. 